Cadernos de História, Belo Horizonte, v. 22, n. 37, Novembro de 2021

DOI: https://doi.org/10.5752/P.2237-8871.2021v22n37p33-52

\author{
DA MAIS VIBRANTE À MAIS \\ TEMIDA - COOPERAÇÃO, RESPEITO, \\ VIRILIDADE E VIOLÊNCIA \\ NA HISTÓRIA DA TORCIDA \\ UNIFORMIZADA DO PALMEIRAS E DA \\ MANCHA VERDE (1971- 1995)
}

Vitor CANALE

Fundação Getúlio Vargas

vitorcanale@gmail.com

\title{
Resumo
}

O movimento das torcidas organizadas, institucionalizado em São Paulo a partir de 1969, tornou-se uma marca nos estádios ao alterar muitos elementos da cultura torcedora. O objetivo deste estudo é apresentar a trajetória das duas principais entidades de torcedores da Sociedade Esportiva Palmeiras: a TUP (Torcida Uniformizada do Palmeiras), criada em 1970, e que congregou a maioria dos torcedores organizados alviverdes até metade da década seguinte, e a Mancha Verde, que concentrou a maioria dos torcedores palmeirenses a partir dos anos 1990. A análise baseada em entrevistas de líderes das torcidas, nos jornais o Estado de S. Paulo, Folha de S. Paulo e na revista Placar, busca refletir quais as imagens que as entidades cultivaram de si mesmas; as relações de cooperação recorrentes ao universo torcedor da década de 1970 e os enfrentamentos entre torcidas durante a década de 1980 e início dos anos 1990. As mudanças ocorridas ao longo de todo o período nos permitiram fazer uma análise das concepções de virilidade e do conceito nativo de respeito, bem como visualizar a relação entre o número de homicídios e crimes violentos em São Paulo e as relações violentas entre os torcedores na cidade.

Palavras-chave: Futebol; Torcida Organizada; Torcedores; Palmeiras; Mancha Verde.

Recebido em 30 de novembro de 2020.

Aprovado em 1 março de 2021. 
Cadernos de História, Belo Horizonte, v. 22, n. 37, Novembro de 2021

DOI: https://doi.org/10.5752/P.2237-8871.2021v22n37p33-52

\title{
FROM THE MOST VIBRANT TO THE MOST FEARSOME - COOPERATION, RESPECT, VIRILITY AND VIOLENCE IN THE HISTORY OF TORCIDA UNIFORMIZADA O PALMEIRAS AND OF MANCHA VERDE $(1971-1995)$
}

Vitor Canale

Fundação Getúlio Vargas

vitorcanale@gmail.com

\begin{abstract}
The movement of supporters' Club, institutionalized in São Paulo since 1969, has become a recurrent aspect in stadiums by changing many elements of the local supporters' club. This study aims to present the path of the two main supporters' entities in the history of Palmeiras: TUP (Torcida Uniformizada do Palmeiras), founded in 1970, which gathered most of Palmeiras supporters until the middle of the following decade, and Mancha Verde, which united most Palmeiras supporters from the1990s. The analysis, based on interviews with leaders of supporters' club, in the newspapers O Estado de S. Paulo and Folha de S. Paulo, and in Placar magazine, aims to reflect what self-images the entities have developed; the recurring relationship of cooperation in the supporters' clubs universe of the 1970s, and the growing confrontations between them during the 1980s and beginning of the 1990s. The changes that occurred during the whole period allow us to analyze the virility conceptions and the native concept of respect, as well as visualize the connection between the growing number of homicides and violent crimes in São Paulo and the increasingly violent relationships between supporters in the city.
\end{abstract}

Keywords: Football; Supporters' Club; Supporters; Palmeiras; Mancha Verde. 


\section{Vitor Canale}

\section{INTRODUÇÃo}

A Sociedade Esportiva Palmeiras, clube criado em 1914, primeiramente, com o nome de Palestra Itália, surgiu com o intuito de reunir italianos e seus descendentes na cidade de São Paulo. A forte ligação entre o clube e a colônia italiana se mantém até os dias atuais e é parte marcante da identidade palestrina/palmeirense. Durante a década de 1940, quando o clube assumiu seu nome atual, houve uma gradual abertura para jogadores de perfis étnicos e nacionais diferentes, o que contribuiu para uma diversificação no quadro de associados, simpatizantes e torcedores da equipe. (STREAPCO, 2018, p.148)

A torcida do Palmeiras, descrita em seu hino como aquela que "canta e vibra", teve, entre seus célebres torcedores, Giovani Capalbo, mais conhecido por João Gaveta. Nascido na década de 1920, acompanhou o clube mesmo após um acidente que afetou sua mobilidade e comunicação. Sua resignação ao torcer e a forma destemperada com que culpava os juízes pelas derrotas eram mostra de uma passionalidade reconhecida como parte de um modo de ser italiano. O clube contava ainda com a charanga do Gino, banda musical que acompanhava a equipe. Tanto o torcedor-símbolo como a banda pertencem à mitologia alviverde e representam os antepassados dos grupos que surgiram nas décadas posteriores.

As torcidas uniformizadas dos principais times da capital paulista representaram a primeira experiência de organização de torcedores de longa duração, criadas entre o fim da década de 1930 e o início da década seguinte; possuíam um estreito vínculo com a diretoria dos clubes e eram voltadas a todo o tipo de torcedores, associados ou não aos clubes (SILVA, 1996; TOLEDO, 2002). O ocaso desses coletivos de torcedores, durante a década de 1950, permanece pouco explorado pela historiografia e suas causas pouco conhecidas.

Somente nos anos finais da década de 1960, novos agrupamentos de torcedores passaram a ser ressaltados na cobertura jornalística do futebol, com o surgimento das primeiras torcidas organizadas em São Paulo. O caráter informal da reunião de torcedores, em sua maioria jovens, e o desejo de demonstrar seu apoio e influenciar a dinâmica dos clubes marcaram os grupos que surgiam pela capital paulista.

$O$ presente artigo se debruça sobre a experiência das duas entidades que congregaram mais palmeirenses, o caso da Torcida Uniformizada do Palmeiras (TUP), criada em 1970, e a Mancha Verde, constituída da fusão da Império Verde, a Inferno Verde e o Grêmio Alviverde, em 1983.

Os treze anos entre a fundação da TUP e a criação da Mancha Verde, bem como a trajetória de ambas são sintomáticas em relação às mudanças ocorridas no futebol paulista e na sociedade paulistana entre o início dos anos 1970 até fins da década de 1980. As relações entre os torcedores organizados de diferentes entidades, a ideologia das torcidas e as representações sobre o que era "honra" e "respeito" - categorias nativas das mais importantes no universo dos torcedores - foram gradualmente se transformando com o aparecimento de novos atores sociais a cada geração de jovens que chegava às torcidas. Para além das questões internas ao universo torcedor, é lícito abordar a dinâmica citadina em que esses torcedores estavam imersos, visto que a cidade de São Paulo passava por um momento de crescimento significativo da violência, vitimizando marcadamente jovens periféricos, contingente representativo no movimento de torcidas organizadas. 
O objetivo deste artigo é pensar como a passagem do tempo, marcado pelas experiências externas e internas ao futebol, reforçou signos de tradição e, dialeticamente, a busca de novas formas de interação e pensamento. Para tanto, a Torcida Uniformizada do Palmeiras e a Mancha Verde não serão consideradas como grupos de ideias homogêneas, tampouco como produtos de seu tempo, mas como entidades em que as disputas entre os projetos de torcer tomam as mais variadas formas e significados.

A metodologia empregada foi a análise qualitativa das notícias dos periódicos $O$ Estado de S. Paulo, Folha de S. Paulo e Placar que fizessem menção às torcidas organizadas em questão, aos seus líderes e a outras figuras representativas das entidades; foram analisadas, também, entrevistas de história oral de longa duração realizadas pelo projeto Territórios do Torcer com lideranças da TUP e da Mancha Verde ${ }^{1}$. A variedade de fontes analisadas buscou contemplar a diversidade de concepções de jornalistas e torcedores sobre a história dos grêmios ${ }^{2}$. Por sua vez, a baliza temporal, entre 1970 e 1995, abarca o início da TUP, torcida organizada palmeirense mais longeva, até o confronto entre torcedores alviverdes e são-paulinos conhecido por "Batalha campal do Pacaembu". Este foi um evento de grande exposição midiática que trouxe consigo políticas públicas visando o fechamento das torcidas e é considerado pela historiografia sobre torcedores como um marco transformador de relações no ambiente futebolístico paulista (TOLEDO, 1996).

\section{TUP, A MAIS VIBRANTE}

Surgida um ano após as primeiras torcidas organizadas paulistas ${ }^{3}$, a Torcida Uniformizada do Palmeiras (TUP) era formada maciçamente por estudantes do colégio do Dante Alighieri, por moradores do bairro da Pompéia, região próxima ao estádio alviverde, e pelos italianos e seus descendentes do bairro do Brás. Para Wanderley "Matheus" Rodak (2014), ex-presidente que acompanhou a fundação, a torcida tinha a capacidade de reunir velhos palestrinos e os jovens palmeirenses, que juntaram suas bandeiras e seus instrumentos para criarem os primeiros patrimônios da TUP.

O uniforme era adereço obrigatório para juntar-se à torcida no estádio e era constituído da camisa verde bordada com os dizeres "torcida uniformizada", calças e sapatos brancos. A cobrança pela padronização era uma iniciativa recorrente em diversas torcidas organizadas, interessadas em marcar seu espaço nas arquibancadas, no imaginário dos outros torcedores e nas relações institucionais do clube.

A torcida rapidamente granjeou apoios dentro do seu estádio, o Parque Antártica,

1 Projeto desenvolvido pela parceria entre o Museu do Futebol e a Fundação Getúlio Vargas entre 2014 e 2015. 2 O presente artigo é parte das investigações da tese "Um movimento em muitas cores: O circuito de relações das torcidas organizadas paulistas entre 1968 e 1988 - Uma história da ATOESP (Associação das Torcidas Organizadas do Estado de São Paulo)", desenvolvida pelo autor sob orientação do professor Bernardo Buarque no PPHBC-FGV e defendida em dezembro de 2020.

3 As primeiras torcidas organizadas paulistas surgiram em 1969, com a fundação da Torcida Jovem Ponte, em Campinas, dos Gaviões da Fiel e da Torcida Jovem do Santos, em São Paulo. No início da década de 1970 surgiram a palmeirense TUP (Torcida Uniformizada do Palmeiras) e a Torcida Jovem do Guarani, futuramente rebatizada de Guerreiros da Tribo. Em 1971 foi fundada a corintiana Camisa 12 e no ano seguinte a Torcida Tricolor Independente. Em 1972, foi também a vez da Leões da Fabulosa, representante da Portuguesa. Ausenta-se desta lista a TUSP (Torcida Uniformizada do São Paulo) por ter sido fundada em 1939, porém a partir de 1969 adotou uma postura e organização semelhante às torcidas organizadas. 


\section{Vitor Canale}

como de Mário Travaglini, na época, funcionário e depois técnico da equipe de futebol, e do diretor social Mário Genovese. A cessão de uma bilheteria desativada na Avenida Francisco Matarazzo para guardar parte do patrimônio e a liberação de ingressos gratuitos pela diretoria palmeirense garantiram condições de existência e a possibilidade de expansão para o grupo. A relação de proximidade entre o grêmio e a Diretoria do clube era percebida como uma troca de apoios e fazia parte do cotidiano de diversas torcidas organizadas. Nos primeiros anos do movimento de torcedores, a autonomia institucional e financeira em relação aos clubes não eram as principais demandas, algo que mudaria substancialmente ao longo da década de 1970, quando se difundiu uma concepção de que torcidas dependentes das benesses dos clubes não teriam autonomia para cobrarem melhorias em momentos de crise. Dessa forma, o que era um apoio recíproco passou a ser visto, gradualmente, como submissão por conta de interesses financeiros e a reafirmação de laços clientelistas.

$\mathrm{O}$ crescimento da TUP podia ser aferido pelas constantes viagens dos torcedores para acompanharem o Palmeiras no interior paulista e em outros estados; havia um anúncio veiculado na capa do jornal Folha de S. Paulo que convidava os torcedores palmeirenses a aderirem à caravana ao estádio do Maracanã, para a partida contra o Botafogo, na Copa Libertadores da América, em março de $1973^{4}$.

Durante sua primeira década de existência, a TUP tentou propagar por seus atos e narrativas duas identidades marcantes, via-se como uma torcida que pretendia levar a paz e fazer a festa nos estádios. O caráter de civilidade e a marca da cooperação entre torcidas eram frequentemente ressaltados no discurso midiático e na forma como Rodak caracterizou sua entidade. Um exemplo marcante disso é o título da reportagem da Folha de S. Paulo: "Essa torcida não briga, não vaia e não quer ser tratada como selvagem" . Retratada como bem-comportada, alegre e divertida, a entidade contava em 1975 com 249 sócios, sendo 35 mulheres. O grêmio de torcedores contava ainda com uma Torcida Infantil, para crianças até 15 anos, e mantinha relações frequentes com outros agrupamentos de palmeirenses como a Torcida Acadêmica do Palmeiras, formada por estudantes do colégio Objetivo da Avenida Paulista e, na época, com 200 sócios.

Segundo Roberto Gonçalves Fontes, vice-presidente da TUP, entrevistado por Narciso James, o principal motivo das brigas que envolviam a torcida era seu contingente feminino, visto que as mulheres não eram respeitadas nos estádios:

Isso sempre foi um sério problema. Pensam que mulher que vai ao futebol não presta, sei lá por quê. (...) O dia que a mulher puder frequentar um jogo de futebol sem problemas, vai haver muito mais gente ${ }^{6}$.

Para o torcedor, as principais desavenças nos estádios ficavam a cargo de adeptos avulsos e a torcida organizada tinha por mérito forjar um maior respeito ao adversário, por isso deveriam ser estimuladas pelos clubes, pelo poder público e pela Federação Paulista de Futebol (FPF). Fontes reconhecia ainda que um dos responsáveis pela violência em São Paulo era o poder público, pela ausência de divisão entre torcidas de clubes adversários e a falta

4 TORCIDA prepara caravana para ver o Palmeiras. Folha de S. Paulo, São Paulo, 06/03/1973, p.1.

5 JAMES, Narciso. Essa torcida não briga, não vaia e não quer ser tratada como selvagem. Folha de S. Paulo, São Paulo, 31/07/1975, p.34.

6 Ibid. 
de entradas separadas, o que afetava diretamente a segurança e a paz nos jogos. A atuação truculenta e desrespeitosa da Polícia Militar era outro problema citado pelo torcedor, que se solidarizava com os adversários agredidos, apesar de sua torcida não ter sofrido nenhum ataque.

O contato com torcidas organizadas de clubes adversários era frequente desde o surgimento da TUP, que se inspirou na criação dos Gaviões da Fiel e da Torcida Jovem do Santos e, por outro lado, serviu de influência na fundação da torcida Ju-Jovem. Segundo Rodak (2014), os palmeirenses teriam ajudado os juventinos na constituição de seu primeiro estatuto, na época, requisito obrigatório para que as torcidas organizadas pudessem frequentar os estádios em São Paulo.

A cordialidade da TUP estava expressa em seu lema: "levamos mais paz aos estádios" e em seu regulamento, que previa:

\begin{abstract}
serão punidos rigorosamente aqueles que provocarem torcidas adversárias e por consequência brigas; vaiar o próprio Palmeiras; desacatar diretores da TUP ou funcionários do clube, criar alvoroço junto aos jogadores ${ }^{7}$.
\end{abstract}

Contudo, tanto nos depoimentos dos torcedores da TUP como nas ponderações feitas pela Polícia Militar na matéria jornalística de 1975, o confronto entre integrantes da entidade e torcedores dos Gaviões da Fiel, ocorrido em abril de 1973, não fora citado. O embate que deixou mais de cinquenta feridos e contou ainda com dois torcedores sequestrados e torturados pelos órgãos de segurança da Ditadura Militar demonstrava que nem tudo era congraçamento e respeito mútuo. Para Antônio Carlos, representante da TUP, sua torcida contava com gente honesta, estudantes, pessoas de boa estirpe social, enquanto os Gaviões da Fiel representavam o oposto da sociedade, demonstrando assim, a quem interessava a violência. (FLORENZANO, 2019, p.24-25).

Como lembra o antropólogo José Paulo Florenzano (2019), as relações que se desenvolvem a partir do surgimento das torcidas organizadas não podem ser analisadas na dicotomia simplificadora entre violência e construção democrática. Pensar os vínculos entre torcidas organizadas é refletir sobre os mais variados espectros de interações.

\footnotetext{
A prática torcedora inaugurada pelas organizadas ensejava tanto a criação do espaço público quanto a instauração do campo de batalha, desvelando uma trajetória cambiante que explorava o imenso leque de alternativas e combinações possíveis situadas entre o combate democrático e o confronto físico. (FLORENZANO, 2019, p.29)
}

A TUP foi uma das filiadas da ATOESP (Associação das Torcidas Organizadas do Estado de São Paulo), entidade criada pelas torcidas organizadas em 1976. A associação tinha o intuito de aproximar as lideranças dos grupos de torcedores paulistas, afinar procedimentos de segurança e hospitalidade e estabelecer a união para reivindicações junto ao poder público e à Federação Paulista de Futebol. A organização era capitaneada por Flávio La Selva, fundador e presidente dos Gaviões da Fiel; Hélio Silva, presidente histórico da Torcida Uniformizada do São Paulo (TUSP); e Cosme Freitas, fundador e presidente da Torcida Jovem do Santos (TJS). Essas pessoas se revezaram na presidência da associação de torcedores durante seu primeiro 


\section{Vitor Canale}

momento de existência ${ }^{8}$. A TUP participou da ATOESP em seus primeiros momentos, quando a entidade organizou um torneio de futebol entre suas filiadas. Porém, a relação entre torcida e entidade foi instável dali em diante.

Uma amostra dessa relação conflituosa ocorreu em 1978 quando representantes das torcidas paulistanas se encontraram com Alfredo Mitidieri, presidente da F.P.F., para alertar sobre os perigos do uso de entorpecentes nos estádios paulistas e a TUP já não constava como participante do evento. Em nota, a torcida palmeirense manifestou os motivos de sua ausência na reunião: não via sentido em encontros coletivos entre torcidas organizadas e Federal Paulista de Futebol, mas estava aberta a reuniões individuais com o mandatário. As motivações do rompimento não foram esclarecidas pela nota pública nem pelo depoimento de Rodak (2014), liderança no período.

Contudo, a ausência da ATOESP não transformava a TUP em uma entidade isolada nas relações entre torcidas, pois no mesmo ano, a entidade buscou a parceria de outras nove torcidas palmeirenses para a organização de um boicote o contra time do Parque Antártica9. Após a derrota contra o Botafogo, a equipe precisaria vencer o Noroeste para manter chances de classificação na Copa Brasil. Para os torcedores, a crise do clube era um misto de desorganização da diretoria, falta de ambição do técnico Jorge Vieira e da má vontade de determinados atletas, com destaque para o artilheiro Jorge Mendonça que, ao ser criticado por um torcedor no treino anterior ao jogo, revidou com uma série de socos e pontapés ${ }^{10}$.

Cada torcida palmeirense buscava uma forma de expressar seu descontentamento, a estratégia da Torcida Uniformizada do Palmeiras era concentrar-se nas entradas do estádio do Pacaembu e tentar convencer o máximo de torcedores a permanecerem do lado de fora. $\mathrm{O}$ Grêmio Alviverde entraria no estádio, mas sem bandeiras e sem batucada, fazendo uma greve de silêncio que só seria interrompida pelas vaias ao time.

O estado de caos no campeonato era reflexo do desgoverno da diretoria. O presidente alviverde, Jordão Bruno Saccomani, era indiciado criminalmente por uma dívida de mais de 100 milhões de cruzeiros, que incluíam empréstimos tomados em instituições bancárias em nome do clube, dinheiro de atletas que seria investido pelo mandatário, além de débitos de ordem pessoal. A fuga do dirigente para Miami obrigou o conselheiro Brício Pompeu de Toledo a assumir emergencialmente a presidência do clube ${ }^{11}$.

A equipe palmeirense foi capaz de encontrar novas forças, mesmo com o ambiente conturbado, se reabilitou na Copa Brasil, chegando à final do torneio, sendo derrotada pelo Guarani. Menos perceptível que os resultados alviverdes, a campanha de 1978 introduziria a prática dos boicotes às partidas como arma de reivindicação dos torcedores palmeirenses e de outras equipes.

Pouco mais de um ano depois, por iniciativa da ATOESP, as principais torcidas organizadas da capital debatiam a viabilidade de um boicote ao campeonato estadual. A

8 A primeira fase da ATOESP compreende sua fundação em 1976 até aproximadamente 1983, quando desaparece dos noticiários. Em 1985, as torcidas organizam-se na ATUESP, (Associação das Torcidas Uniformizadas do Estado de São Paulo), entidade de curta existência e em 1995 a ATOESP é reativada como instrumento contra a políticas de banimento de torcidas e proibições após a Batalha Campal do Pacaembu.

9 TORCIDA promete hoje boicote e vaia no Palmeiras. Folha de S. Paulo, São Paulo, 19/07/1978, p. 34.

10 Ibid.

11 Ibid. 
bandeira que unia as torcidas paulistanas era a reformulação do calendário futebolístico.

Apesar de não fazer mais parte da associação de torcidas, a TUP se mostrava a favor da iniciativa, afirmando que muitos já praticavam o boicote por convicções próprias. Seu presidente, Luis Pereira Pinho, e a torcedora-símbolo e tesoureira, Edi Pascutti, repercutiam as mesmas críticas feitas por outras torcidas organizadas, leia-se: a fórmula confusa do campeonato; a grande quantidade de partidas; a longa fase de classificação; a desvalorização dos clássicos e os altos custos envolvidos em acompanhar equipes com calendários tão vastos. Para os torcedores, o campeonato refletia a insensibilidade da F.P.F. e dos dirigentes dos clubes, que em sua sanha pelos lucros de bilheteria, se esqueciam daqueles que sustentavam o futebol ${ }^{12}$.

O movimento iniciado pelas torcidas organizadas em outubro de 1979 estreitou as relações entre TUP e ATOESP. Duas semanas após o debate sobre o boicote às partidas do Campeonato Paulista, foi apresentado à mídia e à Federação Paulista de Futebol um documento assinado por 25 torcidas organizadas da região metropolitana de São Paulo. O apoio das torcidas alviverdes veio da Torcida Acadêmica do Palmeiras, Força Independente do Palmeiras, Paz no Verdão, Periquitos de Poá, Inferno Verde, Mancha Verde ${ }^{13}$ e Torcida Uniformizada do Palmeiras.

O manifesto, criado a partir de uma assembleia geral dos representantes das torcidas paulistas, repetia muitas das críticas elaboradas desde 1976, além de acrescentar novas observações e sugestões. Os primeiros pontos versavam sobre a fórmula de disputa do Campeonato Paulista: a importância dos clássicos e da rivalidade que era menosprezada pela quantidade de partidas entre os clubes grandes; a necessária implementação de um calendário mais racional para diminuir as partidas de baixo interesse e acabar com a divisão em grupos, mais passível de manipulação e acordos entre os times. A sugestão dos torcedores era um campeonato disputado em turno e returno, com duas partidas entre todas as equipes e finais entre os vencedores de cada turno, com a diminuição de participantes de 20 para 14 ou 16 clubes.

O aumento da inflação em $1979^{14}$ obrigava as torcidas a reivindicarem o congelamento dos valores dos ingressos das gerais e das arquibancadas, setores mais populares do estádio. A proposta previa o reajuste somente para as cadeiras numeradas e outros setores mais caros. $\mathrm{O}$ manifesto questionava: "Não seria uma forma de melhor distribuir a renda nacional? ${ }^{15 "}$

Por fim, o manifesto abordava o retorno dos jogos de aspirantes antes das partidas profissionais, como forma de lazer para a população. O documento advertia a Federação e os clubes de que não seriam os descontos ocasionais e promoções que levariam o torcedor ao estádio, mas condições estruturais melhores, além de segurança, conforto e tabelas

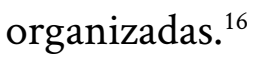

A maioria dos pedidos levados à Federação Paulista de Futebol surtiram pouco ou nenhum efeito. Os reajustes aos ingressos continuaram a acontecer, a tabela do Campeonato

12 TUP começou sua campanha. Folha de S. Paulo, São Paulo, 04/10/1979, p.34

13 A torcida Mancha Verde citada no manifesto era um pequeno grupo de torcedores palmeirenses que não tinha ligação direta com a fundação da homônima Mancha Verde em 1983.

14 A inflação anual, segundo o IGP-DI, de 40,72\%, em 1978, subiu para 77,29\% no ano seguinte.

15 No documento o grito da torcida. Folha de S. Paulo, São Paulo, 18/10/1979, p. 38.

16 Ibid. 


\section{Vitor Canale}

Paulista se mantinha de difícil compreensão e com vários jogos de pouca relevância. Em uma análise comparativa, o Corinthians teve que disputar 47 partidas para sagrar-se campeão paulista em 1979 e o São Paulo disputou 43 jogos para conquistar o título no ano seguinte, em que final foi disputada em partida única, ou seja, pouca coisa havia mudado.

Apesar do pouco sucesso nas tratativas com a Federação Paulista de Futebol, os protestos, cartas, vaias e outros meios de reivindicação teriam uma vida longa. O desejo de transformação das estruturas palmeirenses era o motivador de outras duas cartas abertas da TUP, publicadas em 1980.

No dia 22 de junho, a entidade se posicionava contra a agressão sofrida pelo torcedor Francisco Azevedo. O palmeirense fora atacado pelos atletas César, Gilmar, Baroninho, Carlos Alberto e Ivan quando cobrava maior empenho dos jogadores durante um treino ${ }^{17}$. Pouco tempo depois, em 27 de outubro, a TUP fazia uma avaliação do ano vivido pelo Palmeiras e criticava novamente a falta de profissionalismo dos atletas alviverdes, eximindo de culpa apenas o técnico Diede Lameiro. O momento de crise exigia união de forças dentro do Palmeiras e quem fazia o chamado era José Carlos Rodak, diretor e presidente da TUP:

\footnotetext{
a) apelamos aos verdadeiros palmeirenses para que se unam... b) repudiamos aqueles que pretendem se aproveitar deste momento de imensos desgostos para tirar proveito pessoal... c) achamos que todos têm o direito à crítica, à oposição, mas tudo dentro da honestidade e princípios... d) se o pensamento da TUP vale alguma coisa para os palmeirenses, conclamamos todos a pôr fim às pequenas rivalidade ${ }^{18}$.
}

Ao longo de sua história, a TUP se notabilizou pelas reivindicações, mas seu principal trunfo era a organização da festa nos estádios. Durante a década de 1980, os alviverdes foram tricampeões do troféu Gandula ${ }^{19}$, que era oferecido a atletas, jornalistas e torcidas que se destacavam nos mais variados esportes. Tais títulos, a cura nos detalhes e a performance desses torcedores acabou por sedimentar a alcunha de "a mais vibrante", como até hoje é conhecida.

A torcida organizada teve papel ativo e influência dentro do Palmeiras em diversos momentos decisivos na história do clube, como na adoção do termo "porco" como apelido para os palmeirenses. A palavra começou a ser usada em São Paulo, após a Segunda Guerra Mundial, para referir-se aos italianos apoiadores do fascismo, mas também designava indivíduos de modos sujos e grosseiros. Em 1969, o apelido adormecido voltou a ser insistentemente utilizado pelos corintianos, após o Palmeiras ser o único clube contra a inscrição de dois novos jogadores alvinegros para o lugar dos falecidos Lidu e Eduardo, criando celeumas em uma rivalidade já histórica.

A rivalidade entre Palmeiras e Corinthians teve na disputa simbólica pelo porco outro episódio em 1978, quando torcedores corintianos jogaram um porco pintado de verde no gramado do Morumbi, antes do início do clássico. Segundo Hélio Silva, presidente da Torcida Uniformizada do São Paulo e um dos participantes da peripécia, o porco lhe foi dado por um integrante dos Gaviões da Fiel para que ficasse escondido no estádio do Morumbi. A ajuda do são-paulino para burlar a segurança deu certo e o animal foi entregue aos corintianos que o mantiveram escondido na arquibancada e o lançaram ao gramado quando as equipes

17 ROMEU, esperança do Palmeiras. Folha de S. Paulo. São Paulo, 22/06/1980, p. 15.

18 A POSIÇÃO da TUP. Folha de S. Paulo, São Paulo, 27/10/1980, p.14.

19 Premiação criada pelo jornalista Wilson Brasil. 
se aqueciam. Durante 17 anos, o termo porco foi tratado com xingamento pelos alviverdes. (HOLLANDA; FLORENZANO, 2019 p.118)

O ressurgimento do porco se tornou um projeto desde 1983, quando o diretor de marketing João Roberto Gobatto sugeriu a adoção do símbolo. A novidade foi extremamente mal recebida no Palmeiras, causando a Gobatto a perda do cargo, problemas com as velhas lideranças do clube e o apelido de Porcatto. Em 1984, o esforço em prol do porco partiu da Torcida Uniformizada do Palmeiras, que confeccionou casais de porquinhos de porcelana e os vendeu a 5 cruzeiros. As boas vendas surpreenderam a diretoria e mostraram o potencial do novo mascote. Frente ao sucesso do porco junto à torcida, Cléo, presidente da Mancha Verde, assumia "Agora é porco na cabeça deles (...) os conservadores terão de engolir. ${ }^{20}$ ”

A mascote e o grito caíram no gosto da torcida que entoou ainda timidamente "E dá-lhe porco, e dá-lhe porco, olê, olê, olê2 ${ }^{21 "}$ na vitória contra o Santos em 29 de outubro de 1986 e a plenos pulmões no clássico contra o São Paulo, no 02 de novembro seguinte. Marcelo Lima, da Torcida Uniformizada do Palmeiras e apoiador do porco, aproveitou a oportunidade para provocar os rivais: "Quero ver se os outros vão ter peito de assumir o Gambá ou o Bambi22".

Contudo, a "mais vibrante" não acumularia apenas essa alcunha ao longo de sua existência. Ao longo da década de 1980, a mídia apresentava uma gradual transformação nos modos da torcida palmeirense. O semanário Placar, por meio do repórter Roberto Salim, se propunha a acompanhar a preparação das torcidas organizadas do Palmeiras para o clássico contra o Santos, no dia 29 de outubro de $1985^{23}$.

Segundo Salim, o clima de hostilidade começava antes mesmo do clássico. Durante a semana do jogo, várias torcidas alviverdes receberam ligações com ameaças santistas, por isso, junto das bandeiras e instrumentos, os jovens da TUP mantinham pedaços de pau. Segundo a publicação, aquele era um momento de mudança da torcida alviverde: "A torcida do Palmeiras agora é assim: não some dos estádios nas más fases, grita pelo time, sofre desde 1976 com o jejum de títulos e não enjeita uma boa briga. ${ }^{24 "}$

O presidente da incipiente Brigada Verde fazia coro aos novos tempos: "A torcida do Palmeiras cansou de ser boazinha ${ }^{25 ”}$. A torcida organizada, fundada em 1983 e presidida pelo estudante José Bernardo Cambler Navas, de 22 anos, contava com 500 componentes que, segundo Placar, estavam dispostos a tudo. O nome foi inspirado na torcida da Sampdoria, a Brigate Azzurri, e foi escolhido por ser um nome de guerra.

A ideia dessas torcidas era desatrelar as representações sobre a coletividade palmeirense dos slogans da TUP da década de 1970. Para Navas, a TUP pregava o amor no estádio, mas os torcedores palmeirenses eram sempre os feridos nos confrontos, chegava a hora de um basta. As novas torcidas organizadas do Parque Antártica tinham em comum os nomes belicosos: Boinas Verdes, Falange Verde, Comando Alviverde, a Brigada Verde e a Máfia Verde. Para Matheus Rodak, era o sinal dos tempos:

20 “E DÁ-LHE porco. Placar, São Paulo, 10/11/1986, p. 22.

21 Ibid.

22 Ibid.

23 A GUERRILHA dos verdes. Placar, São Paulo, 15/03/1985 p.32 - 33.

24 Ibid.

25 Ibid. 
Hoje, uma torcida precisa de nome de guerra. Não fica bem criar um grupo e botar o nome de Passarinho Verde ou Flor Verde (...) Os tempos mudaram. Nós criamos a TUP, tínhamos todo um procedimento: todos tinham de usar calças e sapatos brancos e a camisa verde. Hoje não dá mais para se pedir isso. (...) Durante muito tempo, ela foi educada e bem-comportada. Mas as outras torcidas achavam que era covardia. Então mudamos - tivemos de acompanhá-las. São sinais dos tempos ${ }^{26}$.

A TUP encontrava outras torcidas organizadas do Palmeiras no vale do Anhangabaú, ponto de reunião dos ônibus fretados e de saída dos veículos da $\mathrm{CMTC}^{27}$, que iam diretamente para o Morumbi. O ponto de encontro no centro de São Paulo colocava juntos palmeirenses e santistas, que embarcavam lado a lado. O receio de confrontos no Anhangabaú e de emboscadas no caminho eram frequentes, tanto que o presidente tupista, José Carlos Burti, ia à frente do comboio com seu carro para prevenir possíveis enrascadas. Segundo Burti, as emboscadas diminuíram após uma tentativa malfadada de alguns corintianos em agredir palmeirenses no retorno do Morumbi para o Parque Antártica, dizia ainda, "a união entre todas as torcidas é nossa grande arma. Agora sabemos aproveitá-la. ${ }^{28 ”}$

Os enfrentamentos entre torcidas dos grandes clubes paulistas se tornavam mais recorrentes e, no caso palmeirense, estavam relacionados à ausência de títulos, que incomodava desde 1976, e as arbitragens ruins ${ }^{29}$. Essa concepção era presente nos juízos das editorias esportivas da Folha de S. Paulo, Estado de S. Paulo, entre os profissionais da revista Placar e uma parte significativa do depoimento de torcedores alviverdes.

Ricardo Barbosa, um dos criadores da TUP, citava a partida entre Palmeiras e Vasco em que o árbitro Édson Alcântara de Amorim foi criticado por ambos os times pelas expulsões de Mário Sérgio e Jorginho. As falhas de arbitragem atiçaram os ânimos dos palmeirenses, que tentaram agredir a torcida carioca. A situação só foi contornada pela amizade entre as torcidas vascaínas e as torcidas palmeirenses, que organizaram um cordão de isolamento para a segurança dos aliados cariocas.

Segundo Roberto Salim ${ }^{30}$, a violência palmeirense superava a torcida santista e a os corintianos, até então as mais agressivas na capital paulista. Longe de negar os momentos violentos da TUP, Burti reafirmava que a violência não era o objetivo da entidade. $O$ mandatário justificava que o patrimônio de 5 milhões de cruzeiros, investidos em caderneta de poupança, e as mensalidades de 15 mil cruzeiros alimentavam a festa com fogos de artifício, papel higiênico e outros materiais usados nos estádios; além disso, disponibilizavam ingressos e condução aos jogos para os integrantes da torcida. A motivação principal da torcida organizada era a festa na arquibancada e as brigas eram uma das realidades que tinham que enfrentar.

Após a partida contra o Santos, a maioria dos 28.000 torcedores do Morumbi saíram tristes com a derrota palmeirense por dois a um. No entanto, o dia ainda não terminara e chegara ao ônibus da Brigada Verde a notícia de que santistas estavam agredindo crianças e

26 A GUERRILHA dos verdes. Placar, São Paulo, 10/11/1986 p.33

27 Companhia Municipal de Transportes Coletivos

28 Ibid.

29 A narrativa apresentada pelos veículos midiáticos e pelos depoimentos dos torcedores palmeirenses carrega diversas semelhanças com o período de abstinência de títulos do seu principal rival, o Corinthians, entre os campeonatos de 1954 e 1977. Tais narrativas que buscam na passionalidade e frustração dos torcedores a raízes de eventos violentos. 30 Ibid. 
mulheres alviverdes. O ônibus de torcedores se deslocou rumo ao confronto, que terminou sem feridos graves. Ao término do embate, a tônica dessa nova geração de torcedores foi proferida pela diretora de divulgação da TUP, "um pouquinho só de violência não faz mal a ninguém ${ }^{31 "}$.

\section{Da violência em São Paulo}

As mudanças geracionais nas torcidas organizadas, com a constante chegada de jovens vindos de diversas partes da capital, traziam consigo novidades nas práticas, pensamentos e prioridades. Como relatamos anteriormente, a violência, os vínculos de solidariedade e o congraçamento eram faces de uma mesma dinâmica torcedora em constante alternância. No entanto, é explícito nas entrevistas de torcedores, nas notícias jornalísticas e na bibliografia sobre torcidas organizadas o consenso de que as relações violentas aumentaram significativamente ao longo da década de 1980. Muitos são os fatores imputados ao aumento da violência relacionada ao futebol no período, como: os problemas estruturais dos estádios; os encontros ocasionais das caravanas de torcedores pela cidade; o roubo de faixas, bandeiras e outros adereços e o aumento da circulação de armas no país. (TOLEDO, 1996; PIMENTA, 1997).

Ao analisar os dados da violência na cidade de São Paulo, observamos que as décadas de 1980 e 1990 tiveram um aumento acentuado de homicídios e crimes contra o patrimônio, principalmente nos bairros com elevada concentração de trabalhadores de baixa renda (ADORNO, 2019). As taxas de mortalidade por homicídios mostraram um crescimento acelerado entre os anos de 1979 e 1984, um crescimento mais lento entre 1984 e 1986 e uma estabilidade em valores altos até 1994. As maiores taxas de homicídios são relativas a homens, dentre eles os adolescentes e jovens adultos. Em 1984, um adolescente do sexo masculino tinha doze vezes mais chances de morrer por homicídio do que uma adolescente do sexo feminino. (BARATA; RIBEIRO; MORAIS, 1999, p.712-713). Em relação a isso, Cordeiro e Donalisio (2001) asseveram:

Na Região Metropolitana de São Paulo (RMSP), um dos quatro maiores aglomerados urbanos do mundo, os homicídios estendidos foram responsáveis por 2410 óbitos no ano de 1979. A análise dos dados aqui apresentados permite identificar que nos vinte anos subsequentes foram assassinados 130.761 moradores da RMSP, em sua maioria adolescentes e adultos jovens, sendo 92\% deles do sexo masculino. (CORDEIRO; DONALISIO, 2001, p. $670)$.

Os dados apontam estatisticamente os perigos de ser um adolescente ou um jovem adulto na cidade de São Paulo. O risco se apresentava ainda maior para aqueles egressos da classe trabalhadora e integrantes dos bairros da periferia. Os anos entre 1979 e 1984 foram especialmente violentos e coincidem com o aumento de notícias de violência relacionada ao futebol e à belicosidade dos atos. A existência de uma sociedade altamente violenta forja consigo uma cultura de excessos mais recorrentes.

A violência do futebol não surgiu nos anos finais da década de 1970, é uma realidade histórica desde os primeiros momentos do esporte no Brasil (STREAPCO, 2018; SILVA, 1996). No entanto, cada época determinou à sua maneira e sob influências internas e externas

31 Ibid. 


\section{Vitor Canale}

ao campo futebolístico suas práticas de transgressão.

A geração dos fundadores das torcidas organizadas defendia que a violência da época era feita de enfrentamentos esporádicos e não agendados; não utilizavam-se armas de fogo, pois o intuito não era matar; mais do que uma diversão ou provocação, era necessária à defesa da torcida, são raros os casos em que se assumia desejo de provocar dolo (RODAK, 2014; LIMA, 2015).

O surgimento de uma nova geração de torcedores que atingia a adolescência ou a maioridade no final da década de 1970 reformulou muitos dos paradigmas até então sedimentados nas torcidas organizadas, pois estavam providos de outro repertório social em detrimento daquele proposto pelos fundadores das torcidas organizadas paulistanas, significativamente egressos das classes médias.

A forma como cada geração atribuía significado e sentido à violência tinha raízes em suas vivências sociais mais amplas, nos ciclos, caminhos e relações desenvolvidas na metrópole e, no caso do futebol, nas aflições, amarguras, frustrações e humilhações nas relações entre torcedores.

\section{DA Disputa geracional Pelo SENTIDo MORAL do "RESPEITo" OU QUANDO NOVOS ATORES TOMAM AS ARQUIBANCAS DE ASSALTO}

As torcidas organizadas são compostas majoritariamente por homens desde seu surgimento. Locais privilegiados para a expressão da virilidade, ou seja, oportunos para que os jovens possam cumprir a passagem para a vida adulta. A torcida é formadora de uma identidade social, de valores de mundo e de uma subjetividade. Para muitos jovens, se apresenta com a antítese do lar, espaço dos cuidados femininos e da infantilização (BAUBÉROT, 2013). A torcida organizada se constitui como espaço de provar uma masculinidade assentada em valores como a dureza, a resiliência, a coragem e a autoafirmação.

A hegemonia da virilidade nas torcidas organizadas se dá por um discurso que mescla a força física e a firmeza moral, duas características que unem os discursos tanto dos fundadores quanto dos novos grupos de torcedores do final da década de 1970. As diferenças geracionais que tomam corpo na década seguinte trouxeram consigo novos juízos do que seria a firmeza moral dentro de uma torcida organizada.

Para Wanderlei "Matheus" Rodak, a palavra respeito se solidificava nas relações de cooperação entre as torcidas, criando um ambiente de trocas, mesmo que, por vezes, houvesse confrontos, prevaleciam-se alguns valores a serem respeitados. Exemplo disso foi a reação do presidente dos Gaviões da Fiel, citado por Rodak (2014, p.9): "Uma vez a torcida do Corinthians pegou a faixa da nossa torcida infantil, o Flávio La Selva pegou a faixa e foi lá devolver. Então tinha um mínimo de respeito.”

$\mathrm{Na}$ entrevista de Rodak (2014) e nos juízos midiáticos que foram apresentados sobre a TUP, a categoria nativa "respeito" é assemelhada à civilidade e assumida como o principal valor moral da entidade, exemplo disso eram as festas de fim de ano da TUP, em que eram homenageados atletas de outros clubes que se destacaram ao longo do ano. As confraternizações no clube Circolo Italiano contaram com a presença de jogadores como Wladimir e Casagrande, do Corinthians; Muricy Ramalho, do São Paulo; e Rodolfo 
Rodrigues, do Santos, entre os homenageados. Nesse ambiente a virilidade estava atrelada às características que fazem um homem ou grupamento ser visto como adulto, ou seja, a primazia do autocontrole e a capacidade de gerir relações possivelmente conflituosas.

Contudo, o respeito atendia também a outras concepções de mundo concernentes ao prisma da virilidade. Atribuir essa mudança do panorama das torcidas, ocorrido na década de 1980 ao surgimento da Mancha Verde, seria confundir a causa e a consequência, dado que as relações de violência e enfrentamento entre torcidas já eram uma constante na cidade de São Paulo. A adoção de uma concepção de respeito baseada na ideia de ser temido, na capacidade de submeter o adversário ou se fazer respeitar pela violência era uma questão recorrente desde a década de 1970.

Paulo Serdan (2014), fundador e presidente de honra da Mancha Verde, defendeu em depoimento ao projeto Territórios do Torcer que o surgimento de uma nova torcida era resultado de humilhações sofridas pela torcida do Palmeiras frente â violência perpetrada por Gaviões da Fiel e pela Torcida Jovem do Santos. A perda de materiais, como faixas e bandeiras, a impossibilidade das torcidas organizadas do Palmeiras frequentarem eventos, como os jogos da seleção brasileira, foram geradores da revolta e do desejo de suplantar seus algozes.

E aí essa molecada que se juntou na Inferno, que era eu, o Moacir, o Cléo, essa rapaziada, a gente já começou meio que a criar uma família, a gente já estava bem amigos. Aí já tinha outra rapaziada na TUP, também, que estava surgindo: o Marcelo, o Nivaldo, Beto, Cabeção, uns outros caras que também já eram meio contra essa coisa de ficar só levando amor ao estádio e ficar apanhando. Então a gente já estava meio que todo mundo meio se conhecendo, e aí a coisa foi encorpando. E foi quando surgiu a Mancha. E a intenção era essa, era fazer as pessoas nos respeitarem (AQUINO, 2014, p.10).

Uma juventude proveniente das pequenas torcidas palmeirenses e novos torcedores da TUP faziam uma interpretação dos valores torcedores em voga na década de 1980 e prometia devolver o respeito tomado da coletividade alviverde. $\mathrm{O}$ ambiente violento da cidade, as humilhações sofridas e a imposição do valor moral do respeito fomentaram essa dinâmica torcedora.

\section{MANCha Verde, A MAIS TEMIDA}

A torcida organizada Mancha Verde surgiu em 11 de janeiro de 1983, herdando o nome de outra torcida palmeirense, criada no final da década anterior e de vida efêmera. Fruto da união de três pequenas entidades, a Império Verde, a Inferno Verde e o Grêmio Alviverde, a nova torcida nasceu sob o princípio de resgatar o respeito perdido.

A Mancha Verde, homenagem ao personagem da Disney Mancha Negra, se sustentava com a venda de adesivos durante as partidas e com o financiamento de seu primeiro presidente, Dorival Menezes, em seus momentos iniciais. A destituição de seu primeiro mandatário foi sintomática dos princípios que se encontravam em conflito dentro do grupo.

Na verdade, o Dorival caiu numa briga que teve, Mancha e Gaviões, no Morumbi. Foi a primeira vez que a gente realmente enfrentou os Gaviões e acabou levando a melhor, dentro do Morumbi. (...) E a gente estava indo embora, os ônibus subindo, e eu estava até no último ônibus, e eu vi uma camionete na frente e uns ônibus atrás, apagados. Eu falei: "São os caras". Aí pulei a catraca, fui para o motorista, falei: "Vai passando os ônibus, para a gente 


\section{Vitor Canale}

ir avisando". Aí foi avisando, avisando, avisando; a gente parou os ônibus... Porque estavam todas as torcidas juntas. (...) Eu sei que o Cléo tomou uma paulada, caiu no chão logo no começo da briga, e aí a briga acabou. Porque o alvo era o Cléo. Então a gente pegou o Cléo... $\mathrm{E}$ aí os ônibus começaram a andar. E a gente correndo, carregando ele. Aí conseguimos jogar ele para dentro do ônibus, mas ficou um monte de gente para trás. Inclusive eu e uma outra rapaziada. (...) Aí um monte de gente acabou ficando machucada. Nesse dia, a gente acabou resolvendo que aí o Dorival tinha que sair, pela atitude de ter mandado os ônibus andarem e o caramba, sem saber o que estava acontecendo. Porque o Dorival era um cara de paz (AQUINO, 2014, p.12-13).

As palavras de Paulo Serdan, figura histórica da Mancha Verde, demonstram as divergências entre duas formas de gerir uma torcida organizada que não cabiam dentro da mesma agremiação.

As torcidas do Palmeiras, em especial a Mancha Verde, seguiram sua marcha em busca de respeito e despertavam o alerta das autoridades. No clássico contra o Corinthians, em 18 de agosto de 1985, torcedores palmeirenses foram surpreendidos pela polícia portando várias bombas caseiras. O episódio suscitou um evento organizado pela Federação Paulista de Futebol, que reuniu representantes da Polícia Militar, da Federação e das torcidas em busca de soluções de comum acordo para a violência ${ }^{32}$.

Para Nelson Novaes Mardini, diretor da Torcida Tricolor Independente ${ }^{33}$, a cor da violência era verde e branca. $\mathrm{O}$ caminho que a Mancha Verde trilhava em busca de respeito atraía críticos e fomentava divisões entre as torcidas, ocasionando diversos confrontos com a Independente durante os anos 1980 e 1990. A necessidade de prevalecer sobre todos os adversários, ideal comum às duas torcidas, alimentou uma rivalidade exacerbada:

Desta vez foram bombas, mas já vêm acontecendo casos de agressões sempre envolvendo as torcidas do Palmeiras, sobre as quais, repetidas vezes alertamos os responsáveis pela segurança. A VIOLÊNCIA no futebol é tema da reunião na FPF) (FOLHA DE SÃO PAULO, 1985, p. 32).

Segundo torcedores da TUP, a sacola pertencia a Bernardo, membro da Brigada Verde. O torcedor, por sua vez, afirmou ter levado a sacola em seu carro do Parque Antártica ao Pacaembu a mando de Burti e Cléo, respectivamente presidentes da TUP e da Falange Verde, mas acreditava tratar-se apenas de rojões. Mais do que a tentativa de todos os envolvidos de se desatrelarem das implicações do porte de bombas, cabe ressaltar como as lideranças de diversas torcidas palmeirenses tinham um canal frequente de comunicação e atuação conjunta.

Uma semana após a apreensão das bombas caseiras, José Maria Marin, Nabi Abi Chedid e Eduardo José Farah, respectivamente, presidente, vice e assessor da Federação Paulista de Futebol, assistiram à vitória palmeirense contra o São Bento no meio da torcida alviverde. Marin argumentava que sua atitude era uma forma de demonstrar que a torcida não tinha relação alguma com os irresponsáveis que portavam as bombas. Antônio Carlos Romano, torcedor da Mancha Verde, fazia questão de tomar distância do mandatário e denunciar a demagogia envolvida na atitude, visto que na reunião entre torcidas organizadas e a Federação, a Mancha Verde fora duramente desqualificada ${ }^{34}$.

32 A VIOLÊNCIA no futebol é tema da reunião na FPF. Folha de S. Paulo, São Paulo, 22/08/1985, p. 32.

33 Torcida organizada do São Paulo Futebol Clube

34 A TORCIDA geral pela paz. Placar, São Paulo, 30/08/1985, p. 4 - 5. MARIN e Nabi assistem a partida nas

arquibancadas. Folha de S. Paulo, São Paulo, 26/08/1985, p. 20. 
Os enfrentamentos envolvendo as torcidas palmeirenses, com destaque para a Mancha Verde, se repetiram ao longo da década de 1980. No Maracanã, em partida válida pela Copa União, torcedores palmeirenses, apoiados por vascaínos, e flamenguistas, apoiados por corintianos, entraram em confronto em $1987^{35}$.

O dia a dia da torcida envolvia amplas relações com todo o espectro do campo esportivo passando por dirigentes, órgãos de segurança, burocratas do futebol, mídia esportiva e atletas. Ainda em 1987, a Mancha Verde promoveu a festa do troféu Dá-lhe Porco, em que premiou a Revista Placar e o caderno esportivo do jornal Popular da Tarde como melhores veículos da mídia, além de Edu e Júnior, como os destaques palmeirenses do ano ${ }^{36}$.

Os conflitos persistiram no ano seguinte e colocaram novamente em lados opostos torcedores da Mancha Verde e da Independente. O plano dos são-paulinos era atirar rojões nos palmeirenses após uma reunião na sede da Federação Paulista de Futebol, porém, após os disparos e a dispersão, restou apenas o presidente da Independente, Adamastor, que fugiu sozinho para esconder-se em uma farmácia e acabou saindo de lá diretamente para o camburão da Polícia Militar. A reunião, que visava a indicação de cinco torcedores de cada clube para amealharem as críticas e sugestões da torcida, ficou em segundo plano diante do ocorrido. Devido a isso, houve críticas do são-paulino Hélio Silva da TUSP, lembrando que expedientes, como os empregados pela Independente, geravam uma imagem social das mais negativas para o movimento das torcidas organizadas ${ }^{37}$.

Poucos meses depois, aconteceria o episódio mais marcante da história da Mancha Verde. Existem diversas versões sobre a execução do torcedor Cleófas Sóstenes Dantas da Silva, o guerreiro Cléo. O torcedor que foi presidente e símbolo da Mancha Verde era considerado a representação máxima dos valores da entidade.

Conhecido no universo das torcidas organizadas por palmeirenses e pelos adversários, Cléo era um apaixonado pelo clube e exímio brigador ${ }^{38}$, sempre pronto a restaurar e proteger a honra de sua instituição. Executado a tiros na porta da Mancha Verde, foi aventada a possibilidade de revanche de alguma torcida adversário, com as maiores suspeitas voltadas aos Gaviões da Fiel. O sepultamento no cemitério do Araçá, em jazigo pertencente a S.E. Palmeiras, foi acompanhado pelos jogadores Lino, Zetti, Ivan e Marcos, causando comoção na torcida e no clube ${ }^{39}$. Cléo era o presidente em exercício da Mancha Verde e foi substituído pelo colega de muitos anos Moacir Bianchi, o MOA, que também morreu executado a tiros em 2017, na capital paulista ${ }^{40}$.

No domingo, após a morte de Cléo, a Mancha Verde retornou aos estádios em partida contra o Cruzeiro. As homenagens ao torcedor incluíram faixas da campanha do $2^{\circ}$ Batalhão de Choque da PM contra a violência, balões e rojões. Após as homenagens, o que se viu foram mais de quinze minutos de brigas entre cruzeirenses e palmeirenses, a polícia teve dificuldade

35 PALMEIRAS perde outra. O Estado de S. Paulo, São Paulo, 08/11/1987, p. 40.

36 A Mancha Verde não possuía o mesmo costume da Torcida Uniformizada do Palmeiras de premiar os destaques dos clubes adversários. PLACAR recebe prêmio. Placar, São Paulo, 09/11/1987, p.65.

37 REUNIÃO de torcidas uniformizadas na FPF acaba em "bombardeio”. Folha de S. Paulo, São Paulo, 21/06/1988, p. A22.

38 Alcunha nativa dada àqueles que se destacam nos confrontos físicos.

39 CHEFE da 'Mancha Verde' é morto a tiros na sede. Folha de S. Paulo, São Paulo, 19/10/1988, p. D2; PAULINHO combate as críticas. O Estado de S. Paulo, São Paulo, 19/10/1988, p. 18; MANCHA de sangue. Placar, São Paulo, n. 960, 28 out. 1988, p. 35.

40 Cf. El Pais (2017). 
em controlar a situação e fez o uso de disparos para o alto como tentativa de dispersar os torcedores. Os ônibus da torcida visitante foram depredados e os cruzeirenses tiveram que ser escoltados ${ }^{41}$. Um dos motivos citados para o início das hostilidades teriam sido os gritos da torcida mineira: “- Cléo morreu, a Mancha se fudeu!"42

No dia seguinte, foi celebrada a missa de sétimo dia do presidente manchista que levou torcedores, atletas e dirigentes ao ginásio da Sociedade Esportiva Palmeiras. O clima de revolta e a sensação de impunidade eram a tônica dos torcedores que buscavam vingança ${ }^{43}$.

A descrença de que as investigações da $23^{\text {a }}$ Delegacia de Polícia da capital paulista levassem aos autores do assassinato e a fama de torcida organizada mais violenta de São Paulo fazia daqueles torcedores, na noite de 24 de outubro de 1989 no Parque Antártica, o centro do furacão das contradições do ethos da masculinidade viril, em que a violência, a dor, a impotência se mesclavam no adeus ao guerreiro Cléo.

Segundo O Estado de S. Paulo, "um momento de religiosidade que está longe de significar o fim da brutal e indesejável violência nos estádios, uma das principais causas de afastamento do público." ${ }^{44}$. A morte de Cléo funcionava assim como elo entre o passado recente de enfrentamentos e o prenúncio de um futuro pouco auspicioso.

\section{CONSIDERAÇÕES FINAIS}

O fardo de sustentar o "respeito" e a "honra" dentro de uma torcida organizada e na relação com seus rivais atendeu a diversos sentidos dentro da experiência dos torcedores palmeirenses. A recorrência de termos como abnegação, vontade e luta denotam um universo de tensões e valores morais que regem a vida das organizações e de seus adeptos. Nesse sentido, a vida dos primeiros anos da Torcida Uniformizada do Palmeiras e os primeiros anos da Mancha Verde são complementares e símbolos de experiências diversas sobre a virilidade como apresentada por Bourdieu:

\footnotetext{
O privilégio masculino é também uma cilada e encontra sua contrapartida na tensão e contensão permanentes, levadas por vezes ao absurdo, que impõe a todo homem o dever de afirmar, em toda e qualquer circunstância, sua virilidade. Na medida em que ele tem como sujeito, de fato, um coletivo - a linhagem ou a casa -, que está, por sua vez, submetido às exigência imanentes à ordem simbólica, o ponto de honra se mostra, na realidade, como um ideal, ou melhor, como um sistema de exigências que está voltado a se tornar, em mais de um caso, inacessível. A virilidade, entendida como capacidade reprodutiva, sexual e social, mas também como aptidão ao combate e ao exercício da violência (sobretudo em caso de vingança), é, acima de tudo, uma carga (BOURDIEU, 1999, p.64).
}

Nos primeiros anos da TUP, a concepção de virilidade apresentava-se sob o signo do respeito mútuo nas relações internas à torcida e com seus adversários. A figura, os ideais e os discursos de Wanderley Matheus Rodak são confirmações do desejo de uma atuação torcedora em que os valores morais estivessem acima da rivalidade clubística.

"A mais vibrante" tinha em sua civilidade e na performance torcedora da arquibancada, seus norteadores; porém, os jovens que acorriam à torcida organizada trouxeram consigo novas formas de pensar. Assim, velhos e novos valores se entrelaçavam na experiência dos

41 PALMEIRAS bate Cruzeiro; torcidas 'guerreiam' no estádio. Folha de S. Paulo, São Paulo, 24/10/1988, p. D8.

42 Ibid.

43 TORCIDAS provocam o terror nos estádios. O Estado de S. Paulo, São Paulo, 25/10/1988, p.16.

44 Ibid. 
líderes dos anos 1980, Marcelo Lima, longevo presidente da TUP.

Nessa composição entre os valores de paz fundantes da torcida e as concepções de uma vanguarda de jovens que cresceram em uma cidade cada dia mais perigosa, a violência ocupou espaço central. Para essa vanguarda torcedora, retomar o respeito perdido era defender o direito do palmeirense de andar com a camisa do seu clube de cabeça erguida pela cidade sem temer a humilhação de corintianos ou santistas - era o imperativo de uma geração que não vislumbrava mais a solução através do diálogo.

A briga, meio de angariar esse respeito que beneficiaria toda a comunidade palmeirense, também não era destituída de valores ou respeito. O uso de armas de fogo ou armas brancas era uma excepcionalidade, pois o desejo era somente subjugar o adversário e não o matar; assim, mesmo na briga, havia o respeito pela existência humana. Como relembra Marcelo Lima:

Brigava, brigava mesmo, bati mesmo, bati muito mesmo, apanhei também, mas nunca a gente foi covarde, nós da turma nunca "deixava" ninguém bater até a morte, muito menos roubar o tênis. Mas era uma briga de... de momento, não que se arrastava para a vida do dia a dia (LIMA, 2015, p.6).

$\mathrm{Na}$ experiência desses novos líderes de torcida, na década de 1980, os conflitos estavam enredados em uma complexa teia de sentidos, pois brigava-se para proteger o direito de todo palmeirense demonstrar publicamente sua afeição pelo time; mas a briga poderia levar à morte de um companheiro e deixar sequelas na comunidade. $\mathrm{O}$ caso do assassinato do manchista Cléo e as marcas desse evento na comunidade palmeirense reforçam a sensação de que as obrigações impostas pela virilidade são antes de tudo um pesado fardo.

(...)o Cléo provocava os caras, os caras provocavam o Cléo. Só que o Cléo era inocente. Ele
te enchia o saco, mas ele era inocente. Ele amava o Palmeiras, ele achava, como eu achava,
que a gente se encontrava no meio de semana, dez cara parava ali, vinha os corintianos, nós
batíamos. Porque a gente tinha que recuperar a honra do torcedor palmeirense de voltar
usar a camisa, porque não usava. Não vem falar que foi só a Mancha, que é cascata. Não exis-
te. Foi todo mundo. Isso foi o sacrifício de uma cem pessoa. Que muitos morreram, estão
presos, estão desvalorizados. É uma palhaçada, na real. Coisa besta. Ficar batendo nos ou-
tros, meia noite, dando paulada na cabeça, para poder usar a camisa no outro dia. Uma puta
falta de... Uma idiotice. Eu tenho até vergonha de falar esses bagulhos. (LIMA, 2015, p.22)

A vida de Cléo, seus feitos, sua trajetória em busca do respeito para a coletividade palmeirense, ao mesmo tempo em que se constituíam em expressão da honra deixaram uma carga de revolta e de vingança que traria muitos outros enfrentamentos na década de 1990.

O surgimento de novas lideranças na TUP e a escalada da Mancha Verde foram amplamente noticiados pela mídia, durante a década de 1990, por conta de incidentes violentos que tiveram seu ápice de belicosidade e de repercussão pública com a "Batalha campal do Pacaembu”. Este foi um conflito entre torcidas do Palmeiras e do São Paulo, que ocorreu ao final da partida decisiva da Super Copa São Paulo de Futebol Júnior, em 20 de agosto de 1995. O Pacaembu em reforma foi o palco do enfrentamento que acabou com a morte de Márcio Gasparin. Para Marcelo Lima (2015), “(...) a ideologia do torcedor organizado acabou naquele dia." (LIMA, 2015, p. 18).

A política de proibições e de fechamentos de torcidas organizadas, levada a cabo pelo Ministério Público Federal, na figura do procurador Fernando Capez, obrigou a TUP e a 
Mancha a buscarem subterfúgios para continuarem a existir e a angariar novos adeptos.

Após a prisão de Marcelo Lima, que não estava presente na partida, e um período de fechamento, a Torcida Uniformizada do Palmeiras pôde retomar suas atividades (LIMA, 2015). Para a Mancha Verde, as implicações foram mais graves, permaneceu mais de dois anos impedida de frequentar os estádios e com seu processo de extinção em julgamento. A torcida organizada, que dava seus primeiros passos no carnaval paulistano, encontrou no samba uma saída jurídica para a sua existência. Refundada como Mancha Alviverde, em 1997, entrou para o desfile de blocos carnavalescos na cidade de São Paulo e pôde organizar sua caravana ao Maracanã para a final do Campeonato Brasileiro entre Palmeiras e Vasco ${ }^{45}$. 


\section{REFERÊNCIAS BIBLIOGRÁFICAS}

ADORNO, S.; NERY, M. B. Crime e violência em São Paulo: retrospectiva teórico-metodológica, avanços, limites e perspectivas futuras. Cadernos Metrópoles, São Paulo, v. 21, n. 44, p. 169-194, jan./abr. 2019.

BARATA, R. B.; RIBEIRO, M. C. S. de A.; MORAES, J. C. de. Tendência temporal da mortalidade por homicídios na cidade de São Paulo, Brasil, 1979-1994. Cadernos de Saúde Pública, Rio de Janeiro, v. 15, n. 4, p. 711-718, 1999.

BAUBÉROT, Arnaud. Não se nasce viril, torna-se viril. In: CORBIN, Alain; COURTINE, JeanJacques; VIGARELLO, Georges. História da virilidade. Petrópolis, Editora Vozes, 2013.

BOURDIEU, Pierre. A dominação masculina. Rio de Janeiro: Bertrand Brasil, 1999.

CORDEIRO, R.; DONALISIO, M. R. C. Homicídios masculinos na Região Metropolitana de São Paulo entre 1979 e 1998: uma abordagem pictórica. Cadernos de Saúde Pública, Rio de Janeiro, v. 17, n. 3, p. 669-677, 2001.

EL PAÍS. Disponível em: https://brasil.elpais.com/brasil/2017/03/03/ deportes/1488572872_937970.html. 03/03/2017. Acessado em 10 de janeiro de 2020.

FLORENZANO, José Paulo. A república dos torcedores. In: HOLLANDA, Bernardo Borges Buarque; FLORENZANO, José Paulo. Territórios do torcer - Depoimentos de lideranças das torcidas organizadas de futebol. São Paulo: Educ, 2019.

HOLLANDA, Bernardo Borges Buarque; FLORENZANO, José Paulo. Territórios do torcer Depoimentos de lideranças das torcidas organizadas de futebol. São Paulo: Educ, 2019.

PIMENTA, Carlos Alberto Máximo. Torcidas organizadas de futebol: violência e autoafirmação: aspectos da construção das novas relações sociais. Taubaté: Vogal, 1997.

SILVA, Elisabeth Murilho. As "torcidas organizadas de futebol”: violência e espetáculo nos estádios. São Paulo. Dissertação (Mestrado em Ciências Sociais) - Pontifícia Universidade Católica de São Paulo (PUC-SP), São Paulo, 1996.

STREAPCO, João Paulo França. Cego é aquele que só vê a bola - O futebol paulistano e a formação de Corinthians, Palmeiras e São Paulo. São Paulo: Edusp, 2018.

TOLEDO, Luiz Henrique. Torcidas organizadas de futebol. Campinas: Autores Associados, 1996.

\section{Depoimentos}

AQUINO, Paulo Rogério de. [Depoimento] Rio de Janeiro: Cpdoc/Fundação Getúlio Vargas, 2014. $3 \mathrm{~h} 12$.

LIMA, Marcelo Moisés Moura. [Depoimento] Rio de Janeiro: Cpdoc/Fundação Getúlio Vargas, 2015. $1 \mathrm{~h} 50$.

RODAK, Wanderley Matheus. [Depoimento] Rio de Janeiro: Cpdoc/Fundação Getúlio Vargas, 2014. 1 h 57.

SANTOS, Jânio Carvalho. [Depoimento] Rio de Janeiro: Cpdoc/Fundação Getúlio Vargas, 2014, $3 \mathrm{~h} 50$. 